\title{
Long non-coding RNA-Low Expression in Tumor inhibits the invasion and metastasis of esophageal squamous cell carcinoma by regulating p53 expression
}

\author{
PENG-LI WANG*, BIN LIU*, YANG XIA, CHUN-FENG PAN, TENG MA and YI-JIANG CHEN \\ Department of Thoracic and Cardiovascular Surgery, The First Affiliated Hospital of Nanjing Medical University, \\ Nanjing, Jiangsu 210029, P.R. China
}

Received March 13, 2015; Accepted January 12, 2016

DOI: $10.3892 / \mathrm{mmr} .2016 .4913$

\begin{abstract}
Long non-coding RNAs (lncRNAs) are involved in governing fundamental biological processes, and, in many IncRNAs, the expression level is altered and likely to have a functional role in tumorigenesis, including apoptosis, migration and invasion. The lncRNA-Low Expression in Tumor (LET), a recently identified lncRNA, was demonstrated to be downregulated in hepatocellular and gallbladder cancer. However, its role in esophageal squamous cell carcinoma (ESCC) requires investigation. The expression level of lncRNA-LET mRNA in primary ESCC and matched healthy tissues (48 cases) was determined by reverse transcription-quantitative polymerase chain reaction. In addition, the effects of IncRNA-LET on cell apoptosis were evaluated by flow cytometric analysis, the regulatory effect of IncRNA-LET on migration was detected using a wound healing assay and cellular invasion was analyzed by Matrigel-coated transwell assay. Furthermore, the effect of IncRNA-LET on cell proliferation was investigated by 5-ethynyl-2'-deoxyuridine cell proliferation assay and protein levels of IncRNA-LET targets were analyzed by western blotting. IncRNA-LET expression was decreased in primary ESCC tissues when compared with paired healthy tissues, and was identified to be associated with the clinical features. Overexpression of 1ncRNA-LET was observed to inhibit the migration and invasion of ESCC cells, and modulate p53 expression levels in human ESCC cell lines in vitro. These results establish that lncRNA-LET is significant in the
\end{abstract}

Correspondence to: Professor Yi-Jiang Chen, Department of Thoracic and Cardiovascular Surgery, The First Affiliated Hospital of Nanjing Medical University, 300 Guangzhou Road, Nanjing, Jiangsu 210029, P.R. China

E-mail: yijiangchenkxy@126.com

${ }^{*}$ Contributed equally

Key words: long non-coding RNA-Low Expression in Tumor, lentivirus, p53, esophageal squamous cell carcinoma cells, migration, invasion regulation of tumor progression and metastasis, and serves as a tumor suppressor in, and therefore has therapeutic potential for, the treatment of human ESCC.

\section{Introduction}

Esophageal squamous cell carcinoma (ESCC), a highly lethal malignancy, is the eighth most common cancer worldwide and the sixth most common cause of cancer-associated mortality (1). Furthermore, ESCC has become one of the most common types of malignant tumor in China, Japan and Southeast Africa $(2,3)$. In China, ESCC is the predominant subtype and contributes to $\sim 90 \%$ of all esophageal cancers (ECs) (4,5). Despite the use of multimodal treatments, such as radical surgery, chemotherapy and radiotherapy, the overall prognosis for ESCC remains poor, with 5-year survival rates of 5-45\% (6-8). Although previous studies have demonstrated that alterations of numerous oncogenes and tumor-suppressor genes are involved in ESCC, the underlying molecular and genetic mechanism of esophageal carcinogenesis remains largely unknown (9).

Long non-coding RNAs (lncRNAs), with transcripts $>200$ nt in length, which were initially recognized to represent random transcriptional noise, have been implicated in numerous biological behaviors, such as epigenetic regulation, chromatin modification, transcription and post-transcriptional processing (10-12). Increasing evidence has revealed the contribution of lncRNAs as proto-oncogenes, tumor suppressor genes and drivers of metastatic transformation (13-15).

IncRNA-Low Expression in Tumor (lncRNA-LET), a recently identified lncRNA located at chromosome 15q24.1, was initially established to be downregulated in hepatocellular carcinoma (16). Recently, it was demonstrated to be vital in the development and progression of gallbladder cancer (GBC) (17). However, the prognostic role of lncRNA-LET in cancer remains unknown and to date, to the best of our knowledge, no data were available regarding the lncRNA-LET expression level and biological role in human ESCC.

In the present study, the expression level of lncRNA-LET was demonstrated to be significantly decreased in ESCC tissues when compared with that of adjacent healthy tissues. Its correlation with clinicopathological factors in ESCC patients 
was also evaluated. Using ESCC cell lines, overexpression of IncRNA-LET by lentivirus-mediated gene transfection was investigated and observed to induce apoptosis, and inhibit invasion and proliferation. In addition, the present study verified that overexpression of IncRNA-LET induced the activation of p53. Thus, the current study indicates that lncRNA-LET has a significant role in ESCC development and may be considered as a potential prognostic factor for the prediction of clinical outcomes in ESCC patients.

\section{Materials and methods}

ESCC specimens. A total of 48 ESCC patients that underwent esophagectomy at The First Affiliated Hospital of Nanjing Medical University (Nanjing, China) between 2012 and 2013 were enrolled in the present study. Tumor specimens and paired healthy esophageal tissue specimens, obtained from a site distant to the cancerous lesion, were immediately snap-frozen in liquid nitrogen and stored at $-80^{\circ} \mathrm{C}$ until total RNA was extracted. No radiotherapy or chemotherapy was conducted in these patients prior to surgery. The clinical data, including age, gender, pathological stage, grade, tumor location and lymph node metastasis were acquired from the medical records. Patients were classified according to criteria set by the World Health Organization (18) and were staged according to the tumor-lymph node-metastasis (TNM) classification system, in which T refers to the size of the ESCC and whether it has invaded nearby tissue, $\mathrm{N}$ refers to whether or not regional lymph nodes are involved, and $\mathrm{M}$ refers to distant metastasis (19). The study was approved by the Research Ethics Committee of Nanjing Medical University. Informed consent was obtained from all of the patients.

Cell culture. Human ESCC cell lines, Eca109 and TE-1 were purchased from the Institute of Biochemistry and Cell Biology of the Chinese Academy of Sciences (Shanghai, China). Cells were cultured in RPMI-1640 medium (both purchased from Gibco; Thermo Fisher Scientific, Inc., Waltham, MA, USA) supplemented with $10 \%$ fetal bovine serum (FBS; Sigma-Aldrich, St. Louis, MO, USA), $100 \mathrm{U} / \mathrm{ml}$ penicillin and $100 \mathrm{mg} / \mathrm{ml}$ streptomycin (Gibco: Thermo Fisher Scientific, Inc.), within a humidified atmosphere containing $5 \% \mathrm{CO}_{2}$ at $37^{\circ} \mathrm{C}$. The duration of the culture was 7 days, and the medium was changed every 2 days.

RNA extraction and reverse transcription quantitative polymerase chain reaction $(R T-q P C R)$ analysis. Total RNA from the tissues and cells was extracted using TRIzol reagent (Invitrogen; Thermo Fisher Scientific, Inc.) according to the manufacturer's protocol. Briefly, $1 \mathrm{ml}$ Trizol was used to lyse cells $\left(5 \times 10^{6}\right.$ cells/well), then $0.2 \mathrm{ml}$ of chloroform was added and the cells were incubated at room temperature for $3 \mathrm{~min}$. After centrifugation at $12,000 \mathrm{x} \mathrm{g}$ at $4^{\circ} \mathrm{C}$ for $15 \mathrm{~min}$, the RNA aqueous phase was transferred to a fresh tube. Then, $0.5 \mathrm{ml}$ isopropanol per $1 \mathrm{ml}$ TRIzol was added, and cells were incubated for $10 \mathrm{~min}$ at room temperature, followed by centrifugation at $10,000 \times \mathrm{g}$ at $4{ }^{\circ} \mathrm{C}$ for $10 \mathrm{~min}$. After washing the RNA pellet with $75 \%$ ethanol, the RNA was dissolved in $0.03 \mathrm{ml} \mathrm{RNase}$-free water and incubated for $10 \mathrm{~min}$ at $55^{\circ} \mathrm{C}$. RNA was reverse transcribed into cDNA using the PrimeScript
RT reagent kit (Takara Biotechnology Co., Ltd., Dalian, China). The following thermal cycling protocol was used for reverse transcription: $37^{\circ} \mathrm{C}$ for $15 \mathrm{~min}$ for 3 cycles, followed by $85^{\circ} \mathrm{C}$ for $5 \mathrm{sec}$. The cDNA template was amplified by qPCR using the SYBR Premix Ex Taq (Takara Biotechnology Co., Ltd.) according to the manufacturer's instructions. Briefly, $5 \mu \mathrm{l}$ 10 -fold cDNA was mixed with $10 \mu \mathrm{l} \mathrm{SYBR}$ Premix Ex Taq and $4 \mathrm{nmol}$ of primer in a volume of $20 \mu \mathrm{l}$. The following thermal cycle was followed: $30 \mathrm{sec}$ at $95^{\circ} \mathrm{C}$, followed by 40 cycles of $95^{\circ} \mathrm{C}$ for $5 \mathrm{sec}$, and $60^{\circ} \mathrm{C}$ for $35 \mathrm{sec}$.

The relative levels of LET were determined by RT-qPCR using gene specific primers. Ornithine decarboxylase antizyme (OAZ-1) served as an internal control, and the lncRNA-LET values were normalized to OAZ-1. The RT-qPCR reactions and data collection were performed on a StepOne Plus ${ }^{\mathrm{TM}}$ Real-Time PCR system (Thermo Fisher Scientific, Inc.). The relative expression fold change of mRNAs was calculated using the $2^{-\Delta \Delta \mathrm{Cq}}$ method (20). The primer sequences (Sangon Biotech Co., Ltd., Shanghai, China) were as follows: Forward, 5'-CGAGGACAGAGCCGCCTT-3' and reverse, 5'-GACAAA CCCAGGCGAGATGA-3' for OAZ-1; forward, 5'-GTTGTT GTTGCATTGGGGT-3' and reverse, 5'-AAGATGGAGAGT GGAGCCT-3' for lncRNA-LET.

Plasmid and transfection. The sequence of LET was synthesized and subcloned into PLL3.7-EF-1a-SV40pA (Genewiz, Inc., Suzhou, China), and the expression level of LET was detected by RT-qPCR.

Cells were grown on six-well plates to $70 \%$ confluence and then transfected with the PLL3.7-EF-1a-SV40pA using $10 \mathrm{mg} / \mathrm{ml}$ polybrene (HanBio, Shanghai, China) according to the manufacturer's instructions. Cells were harvested after $48 \mathrm{~h}$ for RT-qPCR and western blot analysis.

Cell migration and invasion assay. Cells (5x10 cells/well) were seeded in six-well plates and cultured in RPMI-1640 medium. After $48 \mathrm{~h}$, cell layers were wounded using the tip of $200 \mu \mathrm{l}$ pipette. After washing cells 3 times with PBS, the serum-free RPIM-1640 medium was added to the plates and incubated within a humidified atmosphere containing 5\% $\mathrm{CO}_{2}$ at $37^{\circ} \mathrm{C}$ for $48 \mathrm{~h}$. Wound closure was observed under a light microscope (DFC500; Leica, Wetzlar, Germany) and measured using AxioVision version 4.7 software (Carl Zeiss Meditec, Dublin, CA, USA).

For the invasion assays, transwell apparatus was used with a polycarbonate membrane (pore size, $8 \mu \mathrm{m}$ ) Boyden chamber insert (EMD Millipore, Billerica, MA, USA) to measure cell motility. The transfected cells and wild-type cells were treated with trypsin/EDTA solution (Sigma-Aldrich) and washed once with serum-containing RPMI-1640 medium. A total of $1 \times 10^{5}$ cells in $0.2 \mathrm{ml}$ serum-free RPMI-1640 medium were seeded on transwell apparatus. Each insert was precoated with $45 \mu \mathrm{g}$ Matrigel (BD Biosciences; San Jose, CA, USA). Prior to examination, the chambers were incubated for $24 \mathrm{~h}$ at $37^{\circ} \mathrm{C}$ in a $5 \% \mathrm{CO}_{2}$ incubator, in culture medium with $10 \%$ FBS in the lower chambers. The cells on the upper surface were scraped using cotton buds and washed away with PBS, whereas the invaded cells on the lower surface were fixed in $100 \%$ precooling methanol (Sigma-Aldrich) for $10 \mathrm{~min}$, stained with $0.05 \%$ crystal violet (Sigma-Aldrich) for $30 \mathrm{~min}$, 
then rinsed in phosphate-buffered saline (PBS; Thermo Fisher Scientific, Inc.) and subjected to microscopic inspection (DFC500; Leica). Finally, the values for invasion were obtained by counting three fields per membrane. Experiments were independently repeated in triplicate.

Cell proliferation assay. The 5-ethynyl-20-deoxyuridine (EdU) detection kit (Guangzhou RiboBio Co.,Ltd., Guangzhou, China) was used to evaluate cell proliferation. According to the manufacturer's instructions, cells were grown on six-well plates to $70 \%$ confluence, treated with $50 \mu \mathrm{M}$ EdU for $2 \mathrm{~h}$ at $37^{\circ} \mathrm{C}$ and fixed with PBS containing $4 \%$ paraformaldehyde (Sigma-Aldrich) for $30 \mathrm{~min}$ at room temperature. After cells were incubated with $2 \mathrm{mg} / \mathrm{ml}$ glycine (Abcam, Cambridge, $\mathrm{UK}$ ) for $5 \mathrm{~min}$ at room temperature, they were treated with 0.5\% Triton X-100 (Sigma-Aldrich) for $10 \mathrm{~min}$ and stained with 1X Apollo reaction cocktail (Guangzhou RiboBio Co., Ltd.) for $30 \mathrm{~min}$ at room temperature. After one wash with 0.5\% Triton X-100 in PBS, 1X Hoechst 33342 (Thermo Fisher Scientific, Inc.) was used to incubate cells at room temperature for $30 \mathrm{~min}$. Images were captured under a confocal laser scanning microscope (LEXT OLS3100; Olympus America, Inc., Center Valley, PA, USA). The assay was repeated in triplicate.

Flow cytometric analysis. The effect of LET treatment on cell apoptosis was determined by flow cytometry. Cells transfected with PLL3.7-EF-1a-SV40pA were plated in six-well plates for $48 \mathrm{~h}$. The cells harvested and fixed in 70\% ice-cold ethanol for $24 \mathrm{~h}$ were collected and analyzed for cell apoptosis using a flow cytometer (FACSCalibur; BD Biosciences). In addition, the cells were harvested and stained with Annexin V/propidium idodide (PI), using the Annexin V-fluorescein isothiocyanate apoptosis detection kit (KGI Biotechnology Co., Ltd., Nanjing, China).

Western blot analysis. Cells harvested from six-well culture plates were lysed using mammalian protein extraction reagent RIPA (Beyotime Institute of Biotechnology, Haimen, China) supplemented with protease inhibitor cocktail (Roche Diagnostics, Basel, Switzerland) and phenylmethylsulfonyl fluoride (Roche Diagnostics). The lysates were then collected and subjected to ultrasonication (Q700 Sonicator; Misonix, Inc., Farmingdale, NY, USA) and centrifugation at $14 \mathrm{~m} 000 \mathrm{x}$ g for $20 \mathrm{~min}$. The supernatants were collected, and protein content was determined using a Bradford assay (Abcam). Protein extractions (50 $\mu \mathrm{g}$ ) were separated by $12 \%$ sodium dodecyl sulfate-polyacrylamide gel electrophoresis (90 min at $100 \mathrm{~V}$; Abcam), then transferred to Immobilon-P polyvinylidene fluoride membranes (EMD Millipore) and incubated with specific antibodies. A GAPDH antibody served as a control. An enhanced chemiluminescence chromogenic substrate (SignalFire ECL Reagent; Cell Signaling Technology, Inc., Danvers, MA, USA) was used to visualize the bands with a chemiluminescent detection system (Pierce ECL Substrate Western Substrate; Thermo Fisher Scientific, Inc.) and then exposed in a Molecular Imager ChemiDoc XRS system (Bio-Rad Laboratories, Inc., Hercules, CA, USA). The intensity of the bands was quantified using Image J software (version 1.42; National Institutes of Health, Bethesda, MD, USA). The rabbit anti-human GAPDH monoclonal antibody
(1:5,000; cat. no. $14 \mathrm{C} 10)$ and rabbit anti-human p53 polyclonal antibody (1:1,000; cat. no. 9282) were purchased from Cell Signaling Technology, Inc.. The secondary goat anti-rabbit horseradish peroxidase-conjugated polyclonal antibody (1:2,000; cat. no. ab6721) was purchased from Abcam. All experiments were performed in triplicate.

Statistical analysis. Statistical analysis was performed using SPSS 20.0 (IBM SPSS, Armonk, NY, USA). Statistical significance was evaluated by Student's t-test or a $\chi^{2}$ test as appropriate. Survival analysis was performed using the Kaplan-Meier method, and the log-rank test was used to compare the differences between patient groups. $\mathrm{P}<0.05$ was considered to indicate a statistically significant difference.

\section{Results}

IncRNA-LET expression level is downregulated in ESCC specimens, and is correlated with pathological grade, tumor stage and lymph node metastasis. The expression levels of IncRNA-LET in 48 pairs of human ESCC and adjacent non-tumor tissue samples were examined by RT-qPCR and normalized to GAPDH. The IncRNA-LET expression level was identified to be significantly downregulated in tumor tissue samples when compared with non-tumor tissue samples. Furthermore, correlation analysis of lncRNA-LET expression levels with clinicopathological features of ESCC patients indicated that the expression level of lncRNA-LET was significantly correlated with the pathological grade $(\mathrm{P}=0.043)$, clinical stage $(\mathrm{P}=0.034)$ and lymph node metastasis $(\mathrm{P}=0.024)$; while there was no significant correlation between lncRNA-LET expression level and gender, age or tumor location (Table I). These results indicate that lncRNA-LET may be involved in the progression and metastasis of ESCC.

IncRNA-LET inhibits ESCC cell migration and invasion in vitro. To investigate the biological role of lncRNA-LET in ESCC progression, Eca109 and TE-1 cells were transfected with PLL3.7-EF-1a-SV40pA-LET. The transfection efficiency was validated using RT-qPCR (Fig. 1). Using a wound healing assay, the relative migrating distance of cells was identified to be significantly reduced in wild-type ESCC cells as compared with the PLL3.7-EF-1a-SV40pA-LET-inf ected cells (Fig. 2). In addition, a Matrigel-coated transwell assay demonstrated that the numbers of PLL3.7-EF-1a-SV4 0pA-LET-infected Eca109 (104 cells) and TE-1 (208 cells) cells that invaded through the Matrigel were significantly less than those of the wild-type Eca109 (200 cells) and TE-1 (509 cells) cells $(\mathrm{P}<0.05$; Fig. 3$)$. These results indicate that IncRNA-LET suppresses the invasive phenotype of ESCC cells in vitro.

IncRNA-LET inhibits ESCC cell proliferation in vitro. To determine whether LET overexpression affected ESCC growth, the EdU assay was performed on ESCC cells infected with PLL3.7-EF-1a-SV40pA-LET. The percentages of EdU-positive cells (cells in the $S$ phase of the cell cycle) in the PLL3.7-EF-1a-SV40pA-LET-infected groups were not identified to be significantly lower than those of the wild-type groups ( $\mathrm{P}>0.05$; Fig. 4). 
Table I. IncRNA-LET expression and clinicopathological characteristics in esophageal squamous cell carcinoma.

\begin{tabular}{|c|c|c|c|c|}
\hline \multirow[b]{2}{*}{ Characteristic } & \multirow[b]{2}{*}{ Cases } & \multicolumn{2}{|c|}{ IncRNA-LET expression } & \multirow[b]{2}{*}{ P-value } \\
\hline & & Low & High & \\
\hline Gender & & & & 0.883 \\
\hline Male & 27 & 16 & 11 & \\
\hline Female & 21 & 12 & 9 & \\
\hline Age (years) & & & & 0.915 \\
\hline$<60$ & 34 & 20 & 14 & \\
\hline$\geq 60$ & 14 & 8 & 6 & \\
\hline Histological grade & & & & 0.043 \\
\hline Well differentiated ${ }^{\mathrm{a}}$ & 15 & 5 & 10 & \\
\hline Moderately differentiated ${ }^{\mathrm{b}}$ & 16 & 10 & 6 & \\
\hline Poorly differentiated $^{c}$ & 17 & 13 & 4 & \\
\hline T stage & & & & 0.034 \\
\hline $\mathrm{T} 1-2^{\mathrm{d}}$ & 18 & 7 & 11 & \\
\hline T3-4e & 30 & 21 & 9 & \\
\hline Lymph node metastasis & & & & 0.024 \\
\hline Negative & 22 & 9 & 13 & \\
\hline Positive & 26 & 19 & 7 & \\
\hline Tumor location & & & & 0.575 \\
\hline Upper and middle $1 / 3$ & 31 & 19 & 12 & \\
\hline Lower $1 / 3$ & 17 & 9 & 8 & \\
\hline
\end{tabular}

$\mathrm{P}<0.05$ is considered to indicate a statistically significant difference. ${ }^{a}$ Tumor was found in the mucosa, submucosa or superficial muscle;

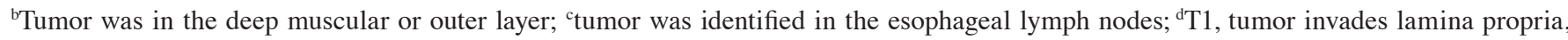
muscularis mucosa or submucosa; $\mathrm{T} 2$, tumor invades muscularis propria; ${ }^{\circ} \mathrm{T} 3$, tumor invades adventitia; $\mathrm{T} 4$, tumor invades adjacent structure. lncRNA-LET, long non-coding RNA-Low Expression in Tumor.

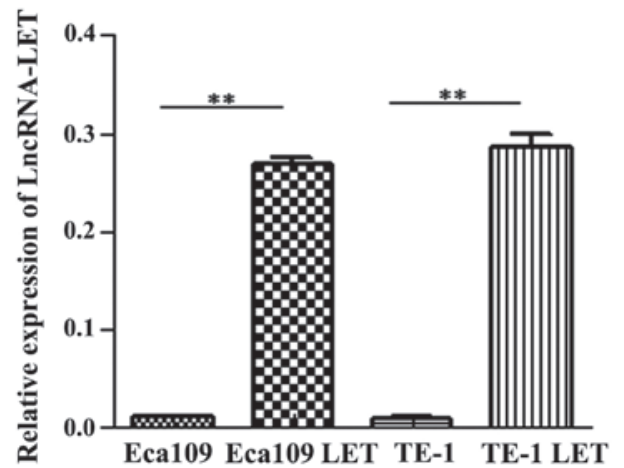

Figure 1. Reverse transcription-quantitative polymerase chain reaction analysis of lncRNA-LET expression levels in esophageal cancer cell line cells, Eca109 and TE-1 following transfection with PLL3.7-EF-1a-SV40pA-LET. ${ }^{* *} \mathrm{P}<0.01$. lncRNA-LET, long non-coding RNA-Low Expression in Tumor.

IncRNA-LET inhibits ESCC cell proliferation via inducing apoptosis. To evaluate the effect of IncRNA-LET on tumor cell apoptosis, Eca109 and TE-1 cells were employed as the model system. It was hypothesized that lncRNA-LET overexpression induced cell apoptosis in ESCC cells. The apoptotic rate of Eca109 and TE-1 cells transfected with PLL3.7-EF-1a-SV40pA-LET was identified to be significantly increased when compared with those of the wild-type ESCC cells (Fig. 5). This indicates that upregulation of LET induces ESCC cell apoptosis in vitro.

IncRNA-LET induces activation of the p53 protein. Recent studies have demonstrated that numerous lncRNAs may participate in the regulation of cell growth by modulating the p53 signaling pathway (21-24). To further investigate whether, and the mechanism by which, LET induces ESCC cell growth arrest and apoptosis, the protein level of p53 was examined following transfection of PLL3.7-EF-1a-SV40pA-LET in wild-type ESCC cells. The results of western blot analysis indicated that the expression level of p53 was significantly increased in ESCC cells transfected with PLL3.7-EF-1a-SV40pA-LET when compared with that of wild-type ESCC cells (Fig. 6). These data indicate that LET functions as a tumor suppressor gene by activating p53 in ESCC cells.

\section{Discussion}

Recent studies have revealed that IncRNAs participate in a multitude of biological processes, such as chromatin modification, transcription and post-transcriptional processing $(10,12,25,26)$. In addition, previous studies have demonstrated that dysregulation of lncRNAs may also affect epigenetic information and provide a cellular growth advantage, resulting in a wide range 
A

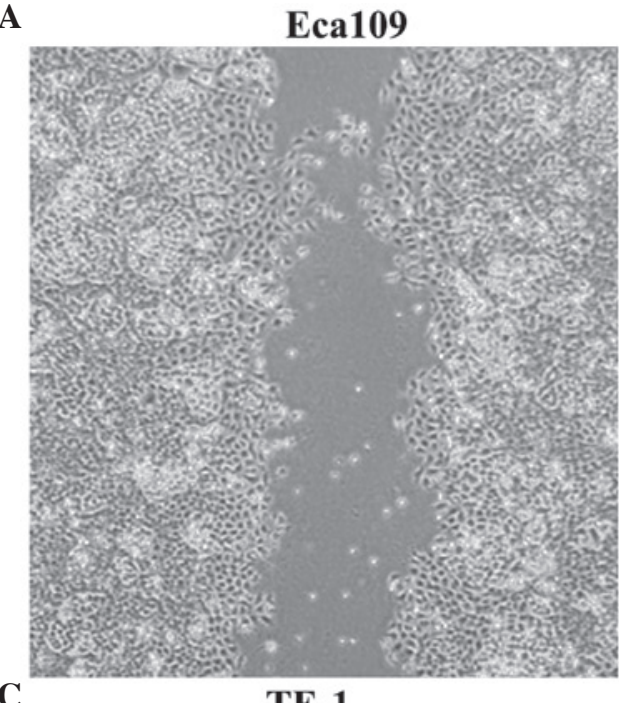

C

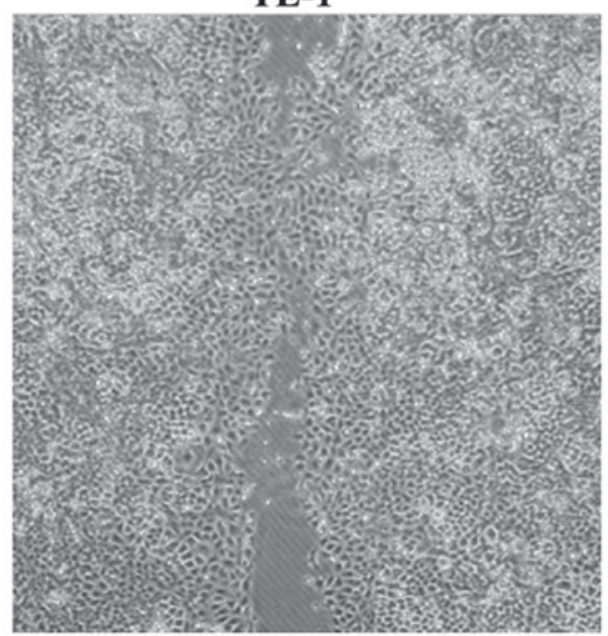

B

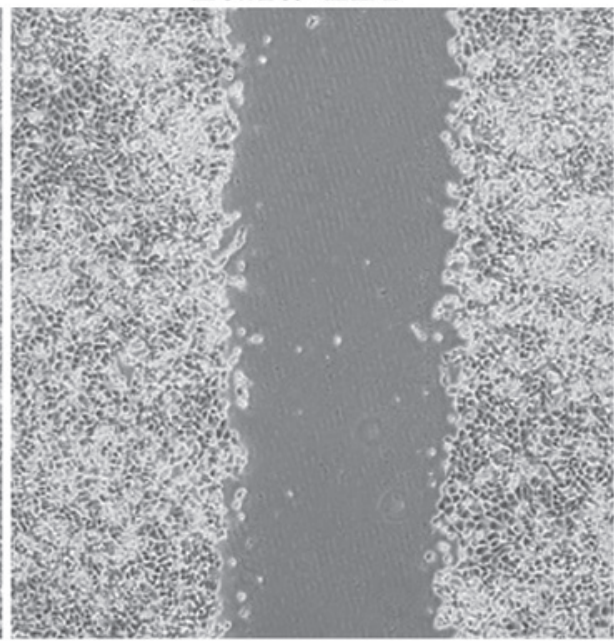

D
Eca109 LET

TE-1 LET

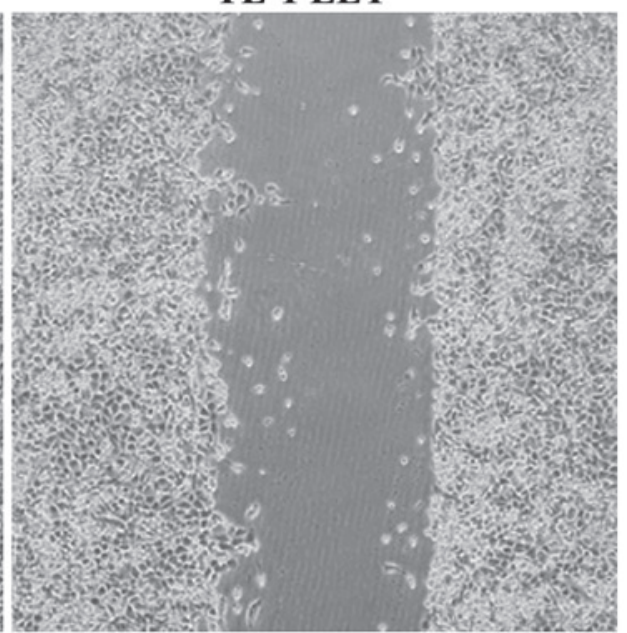

E

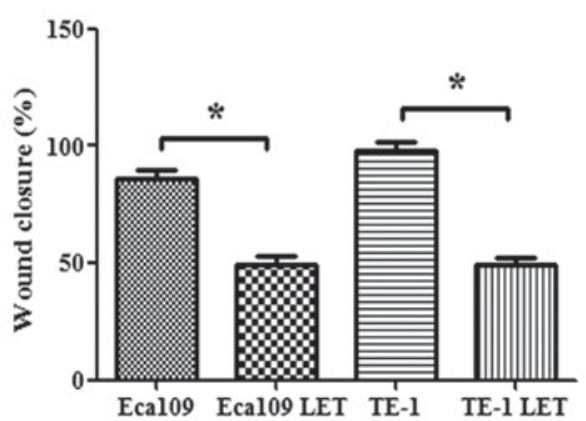

Figure 2. Overexpression of long non-coding RNA-LET inhibits the migration of ESCC cells. Wound healing assay was used to assess the migration ability of ESCC cells. Images represent the cells that have migrated into the wounded area and the histogram demonstrates the relative migration distance of cells. Magnification x200. (A) Eca109 cells; (B) Eca109 cells transfected with PLL3.7-EF-1a-SV40pA-LET; (C) TE-1 cells; (D) TE-1 cells transfected with PLL3.7-EF-1a-SV40pA-LET; (E) percentage of wound closure. "P<0.05. ESCC, esophageal squamous cell carcinoma; LET, Low Expression in Tumor.

of diseases, particularly in progressive and uncontrolled tumor growth $(27,28)$. HOX transcript antisense RNA, a well known IncRNA involved in tumor pathogenesis, has been consistently upregulated and identified as a strong prognosis marker of patient outcomes in various types of human cancer (14,28-30). H19, encoded by an imprinted gene, has been verified to be upregulated in tumors and to possess oncogenic properties (31-33). Maternally expressed gene 3 (MEG3) is located at chromosome 14q32, and a loss of MEG3 expression has been observed in a number of primary human tumors, including glioma, hepatocellular cancers, non-small cell lung cancer, and gastric cancer (34-37). Although evidence of the carcinogenicity of these lncRNAs is strong, the molecular mechanism regarding tumor development and the promotion of metastasis is not fully understood.

IncRNA-LET, as a novel lncRNA molecule, was initially well known for its downregulation in primary hepatocellular carcinoma, wherein IncRNA-LET suppresses cancer invasiveness and metastasis (16). Furthermore, downregulation of IncRNA was examined in squamous-cell lung carcinoma 
A

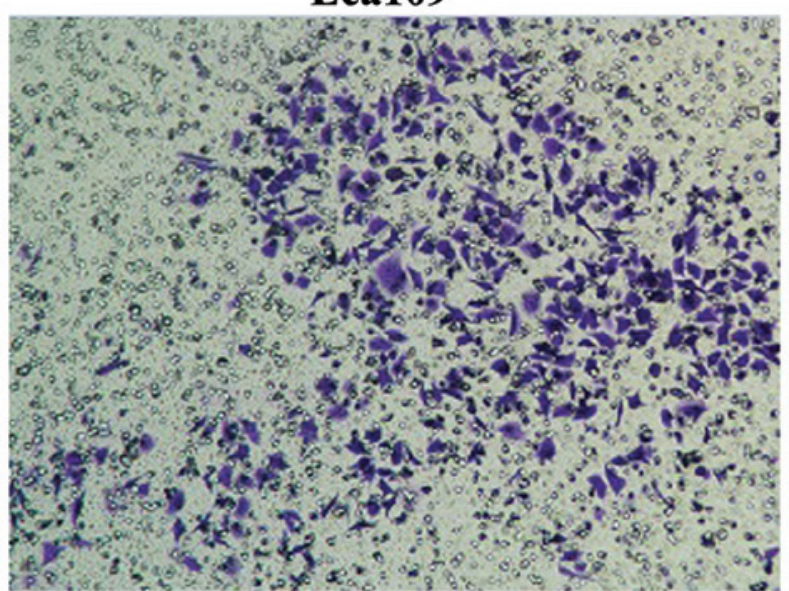

C

TE-1

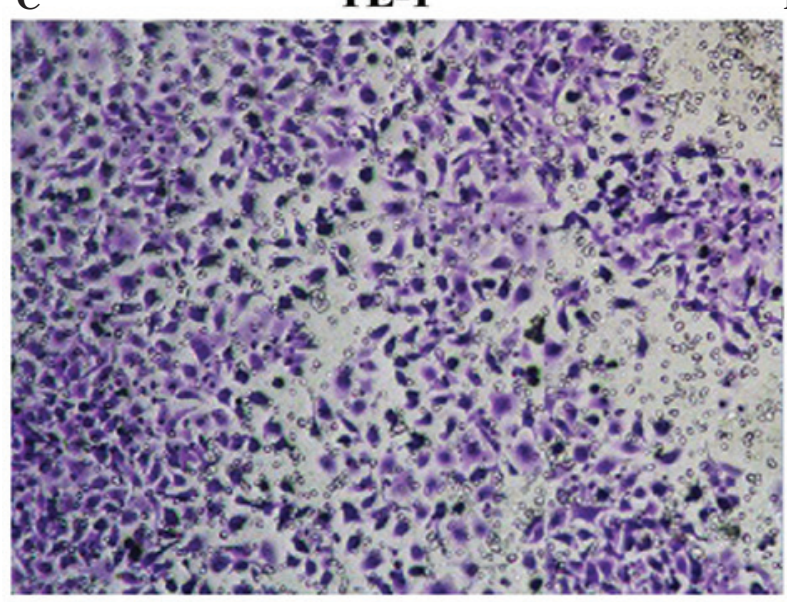

$\mathbf{B}$

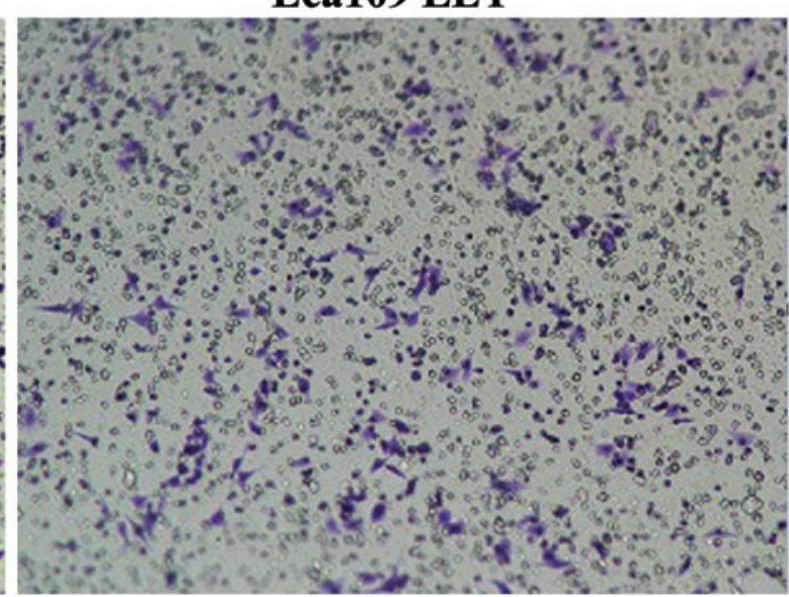

D

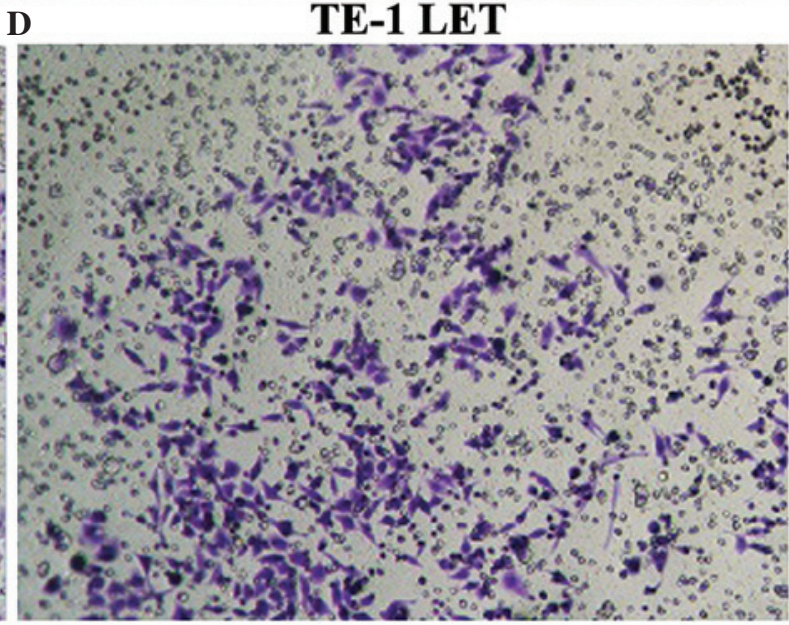

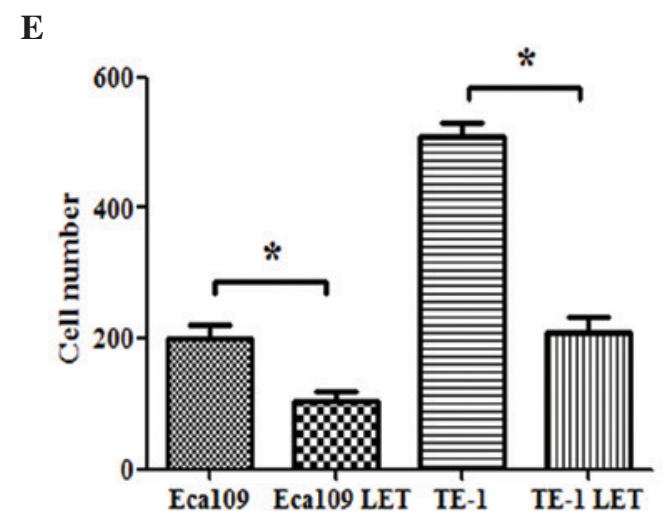

Figure 3. Overexpression of long non-coding RNA-LET inhibits the invasion of ESCC cells. Matrigel-coated transwell assay was used to assess the invasive ability of ESCC cells. The images represent the cells that invaded the matrigel and the histogram demonstrates the number of invasive cells. Magnification x 200; 0.05\% crystal violet stain. (A) Eca109 cells; (B) Eca109 cells transfected with PLL3.7-EF-1a-SV40pA-LET; (C) TE-1 cells; (D) TE-1 cells transfected with PLL3.7-EF-1a-SV40pA-LET; (E) number of invasive cells. "P<0.05. ESCC, esophageal squamous cell carcinoma; LET, Low Expression in Tumor.

and colon carcinoma tissues and compared with their paired healthy primary tissues (16). In addition, there were findings indicating that lncRNA-LET may represent a prognostic marker and potential therapeutic target for GBC (17). Due to the observation that lncRNA-LET is involved with dysregulation during cancer progression, the biological role of lncRNA-LET in ESCC progression was investigated in the present study and its clinical significance was analyzed.

The present study indicated that the expression level of IncRNA-LET was downregulated in ESCC tissue samples when compared with adjacent healthy tissue samples. Furthermore, the low expression level of IncRNA-LET in ESCC tissue samples was demonstrated to be closely associated with clinicopathological features. Low expression levels of IncRNA-LET were correlated with poorly differentiated histology, higher tumor grade and positive nodal status. Similarly, overexpression of lncRNA-LET expression was identified to inhibit the migration and invasion of ESCC cells, and also significantly increased the response of ESCC cells to cell apoptosis induction. 
A
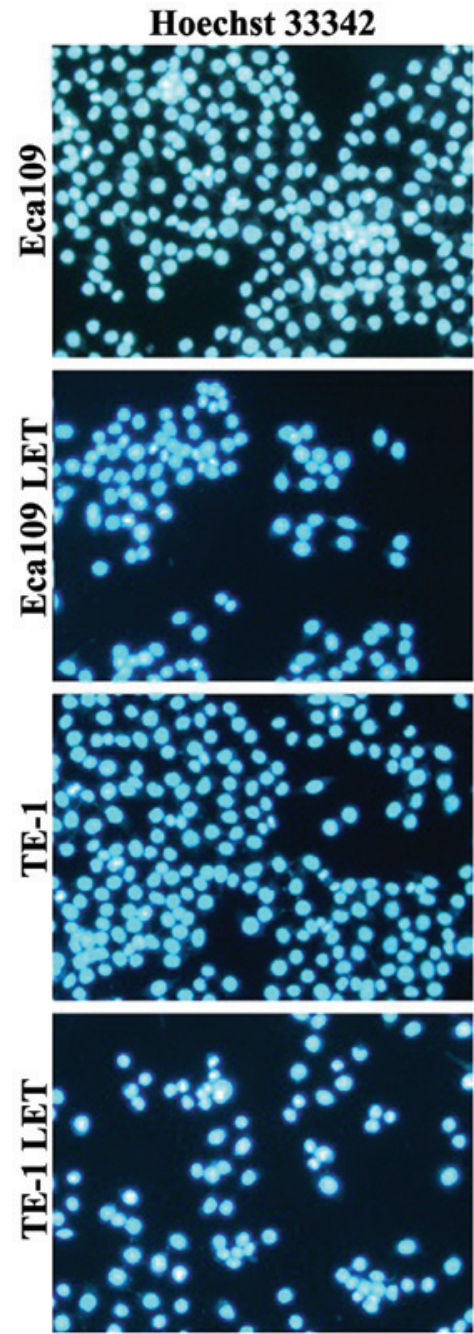
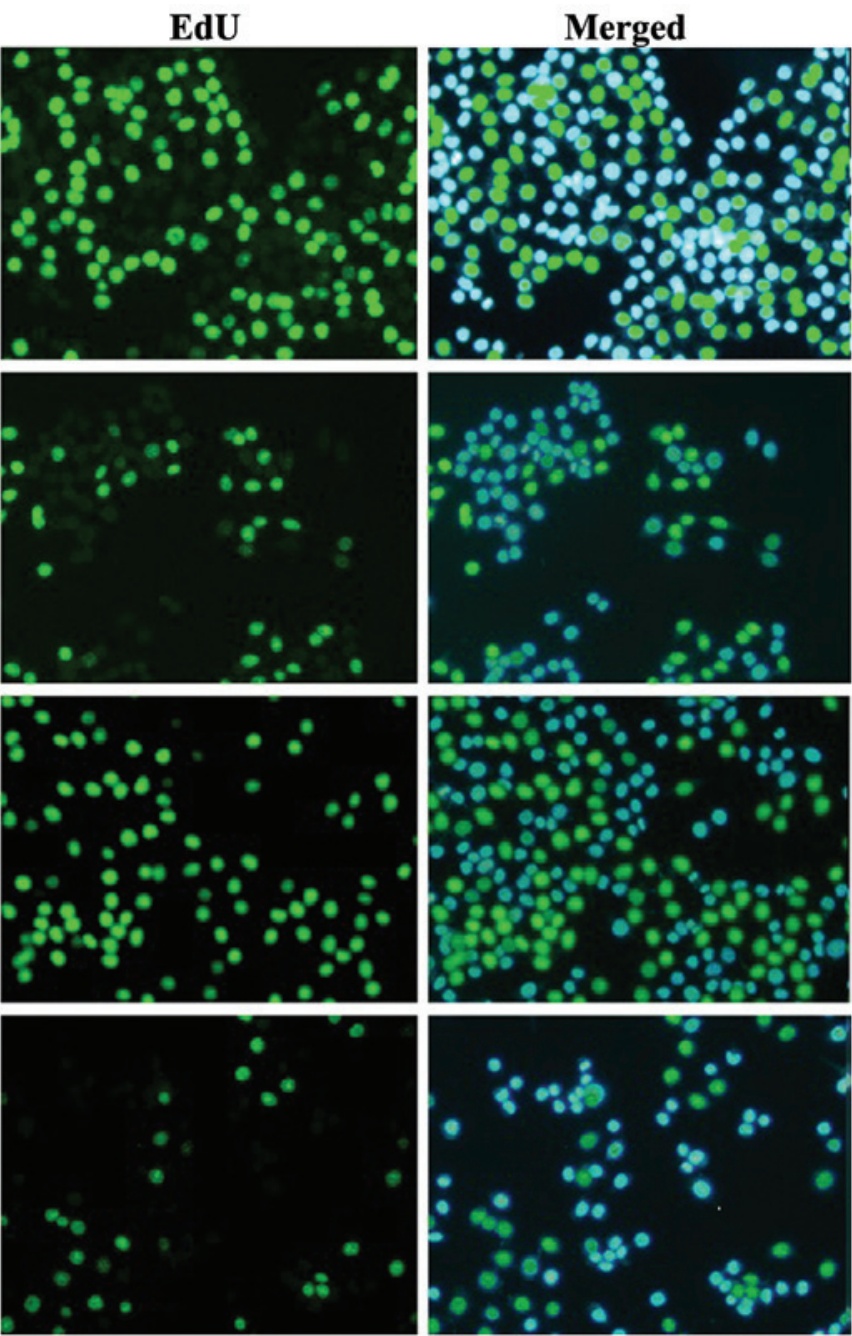

B
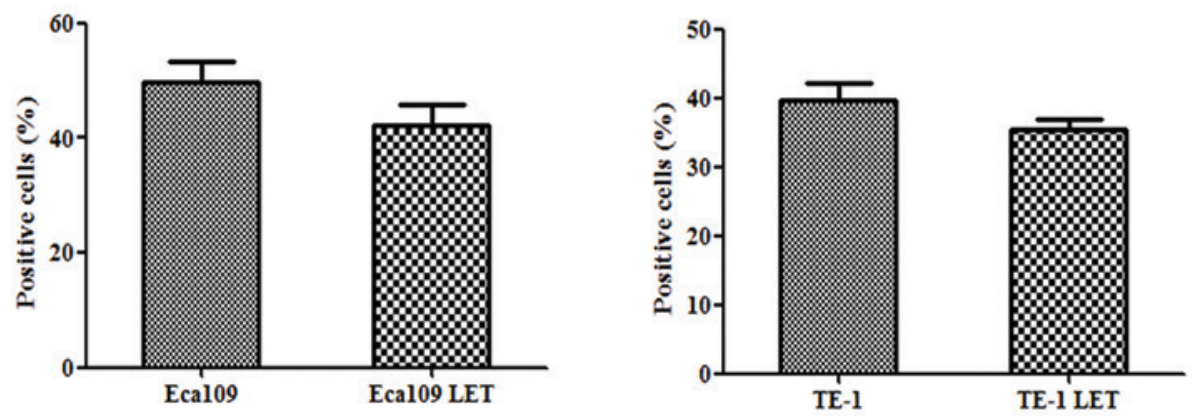

Figure 4. Long non-coding RNA-LET inhibits esophageal cancer cell proliferation in vitro. (A) The EdU assay was performed on esophageal squamous cell carcinoma cells infected with PLL3.7-EF-1a-SV40pA-LET. (B) Percentage of EdU-positive cells. EdU-positive cells in all groups were detected by confocal laser scanning microscopy. The cells were counted in five random fields. Eca109 LET, Eca109 cells transfected with PLL3.7-EF-1a-SV40pA-LET; TE-1 LET, TE-1 cells transfected with PLL3.7-EF-1a-SV40pA-LET. EdU, 5-ethynyl-2-deoxyuridine; LET, Low Expression in Tumor.

p53, as a master regulator for gene expression, directly or indirectly regulates the expression of numerous target genes, which leads to the suppression of tumor development and growth by blocking cell proliferation or by activating cell death programs $(36,38)$. The present study examined whether IncRNA-LET affects the expression level of $\mathrm{p} 53$ protein to further investigate the underlying mechanisms by which IncRNA-LET induced cell growth arrest and apoptosis. Overexpression of lncRNA-LET was identified to significantly increase the level of p53 protein when compared with that of the controls.
In conclusion, the loss of lncRNA-LET expression was demonstrated to be a common occurrence underlying EC, suggesting that lncRNA-LET may perform a key functional role in suppressing the invasive and metastatic behavior of ESCC cells. These findings indicate that lncRNA-LET may function as a tumor suppressor and its deficiency or decreased expression may contribute to ESCC development. Furthermore, IncRNA-LET may be exploited in a promising therapeutic approach for the treatment of EC, and potentially be useful as a novel prognostic marker for EC. 


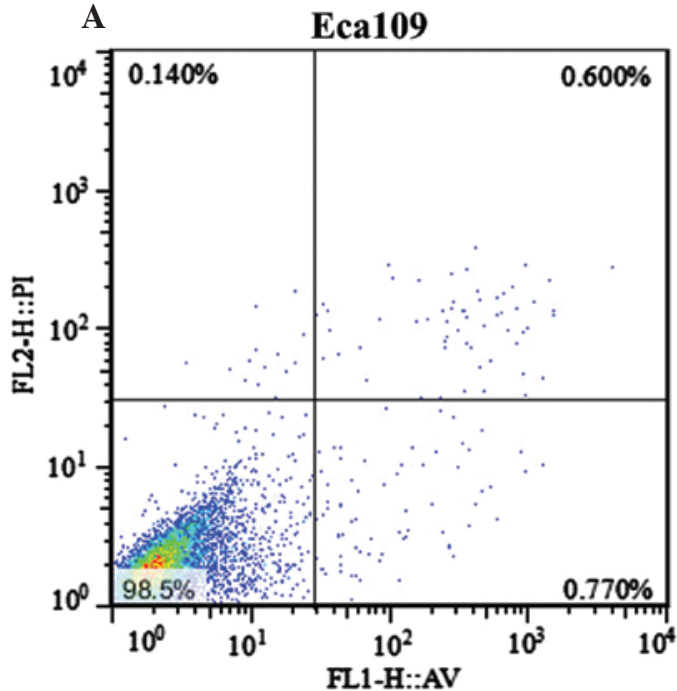

C

TE-1

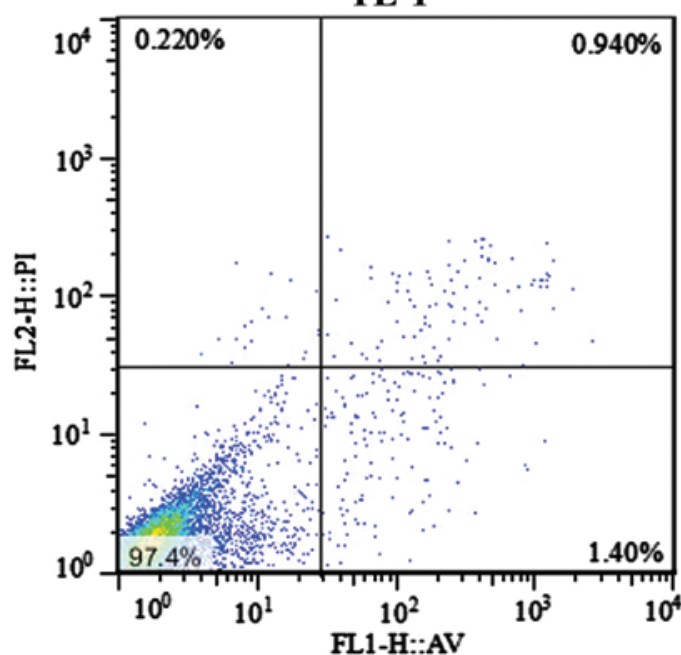

B

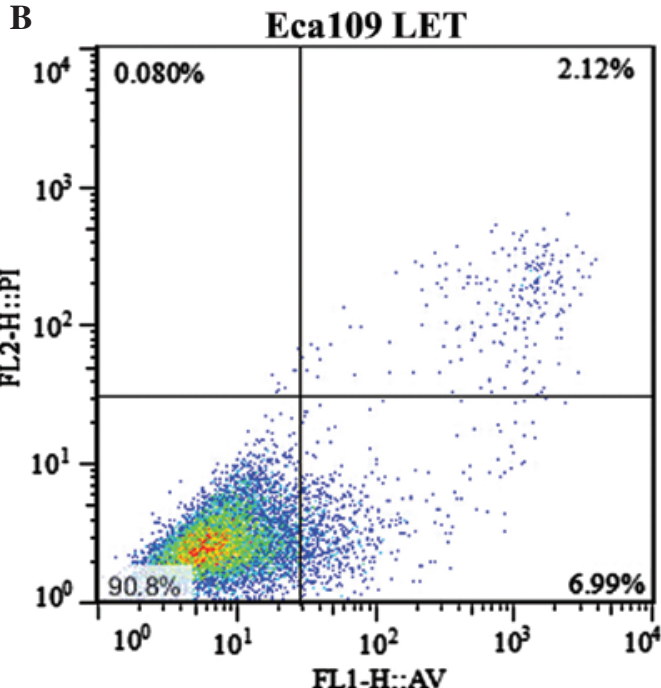

D

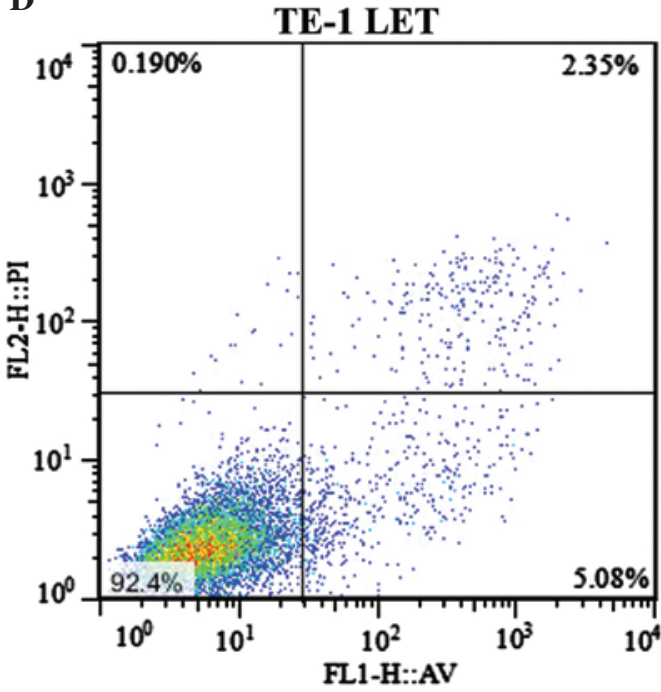

Figure 5. Long non-coding RNA-LET inhibits esophageal cancer cell proliferation by inducing apoptosis. AV/PI staining and flow cytometric analysis were used to assess the apoptosis of Eca109 and TE-1 cells following PLL3.7-EF-1a-SV40pA-LET transfection. (A) Eca109 cells; (B) Eca109 cells transfected with PLL3.7-EF-1a-SV40pA-LET; (C) TE-1 cells; (D) TE-1 cells transfected with PLL3.7-EF-1a-SV40pA-LET. AV, Annexin V; PI, propidium iodide; LET, Low Expression in Tumor.

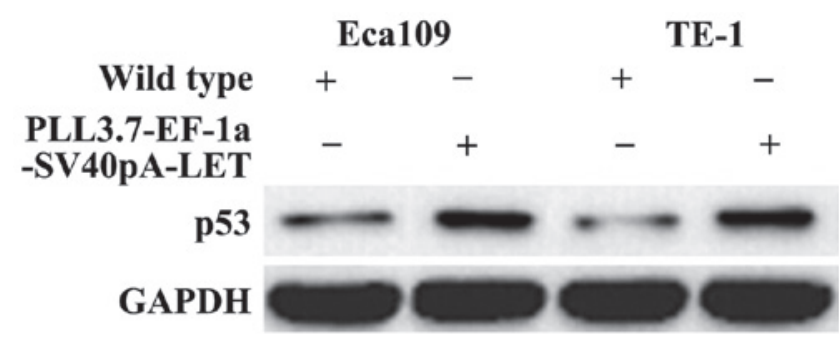

Figure 6. Long non-coding RNA-LET induces activation of p53 protein. Western blot analysis of p53 following PLL3.7-EF-1a-SV40pA-LET transfection. Results from three independent experiments are presented. GAPDH served as an internal control. LET, Low Expression in Tumor.

\section{Acknowledgements}

The present study was supported by the National Natural Science Foundation (grant no. 81170158) and the science and technology project of Jiangsu Provincial Health Department (grant no. H200821).

\section{References}

1. Jemal A, Bray F, Center MM, Ferlay J, Ward E and Forman D: Global cancer statistics. CA Cancer J Clin 61: 69-90, 2011.

2. Enzinger PC and Mayer RJ: Esophageal cancer. N Engl J Med 349: 2241-2252, 2003.

3. Law S and Wong J: Current management of esophageal cancer. J Gastrointest Surg 9: 291-310, 2005.

4. Hiyama T, Yoshihara M, Tanaka S and Chayama K: Genetic polymorphisms and esophageal cancer risk. Int J Cancer 121: 1643-1658, 2007.

5. Li T, Lu ZM, Chen KN, Guo M, Xing HP, Mei Q, Yang HH, Lechner JF and Ke Y: Human papillomavirus type 16 is an important infectious factor in the high incidence of esophageal cancer in Anyang area of China. Carcinogenesis 22: 929-934, 2001.

6. Pohl $\mathrm{H}$ and Welch HG: The role of overdiagnosis and reclassification in the marked increase of esophageal adenocarcinoma incidence. J Natl Cancer Inst 97: 142-146, 2005.

7. Lv XB, Lian GY, Wang HR, Song E, Yao H and Wang MH: Long noncoding RNA HOTAIR is a prognostic marker for esophageal squamous cell carcinoma progression and survival. PLoS One 8: e63516, 2013.

8. Roder JD, Busch R, Stein HJ, Fink U and Siewert JR: Ratio of invaded to removed lymph nodes as a predictor of survival in squamous cell carcinoma of the oesophagus. Br J Surg 81: 410-413, 1994. 
9. Montesano R, Hollstein M and Hainaut P: Genetic alterations in esophageal cancer and their relevance to etiology and pathogenesis: A review. Int J Cancer 69: 225-235, 1996.

10. Wilusz JE, Sunwoo H and Spector DL: Long noncoding RNAs: Functional surprises from the RNA world. Genes Dev 23 1494-1504, 2009.

11. Gutschner T and Diederichs S: The hallmarks of cancer: A long non-coding RNA point of view. RNA Biol 9: 703-719, 2012

12. Mercer TR, Dinger ME and Mattick JS: Long non-coding RNAs: Insights into functions. Nat Rev Genet 10: 155-159, 2009.

13. Tripathi V, Shen Z, Chakraborty A, Giri S, Freier SM, Wu X, Zhang Y, Gorospe M, Prasanth SG, Lal A and Prasanth KV: Long noncoding RNA MALAT1 controls cell cycle progression by regulating the expression of oncogenic transcription factor B-MYB. PLoS Genet 9: e1003368, 2013.

14. Kogo R, Shimamura T, Mimori K, Kawahara K, Imoto S, Sudo T, Tanaka F, Shibata K, Suzuki A, Komune S, et al: Long noncoding RNA HOTAIR regulates polycomb-dependent chromatin modification and is associated with poor prognosis in colorectal cancers. Cancer Res 71: 6320-6326, 2011.

15. Aguilo F, Zhou MM and Walsh MJ: Long noncoding RNA, polycomb, and the ghosts haunting INK4b-ARF-INK4a expression. Cancer Res 71: 5365-5369, 2011.

16. Yang F, Huo XS, Yuan SX, Zhang L, Zhou WP, Wang F and Sun SH: Repression of the long noncoding RNA-LET by histone deacetylase 3 contributes to hypoxia-mediated metastasis. Mol Cell 49: 1083-1096, 2013.

17. Ma MZ, Kong X, Weng MZ, Zhang MD, Qin YY, Gong W, Zhang WJ and Quan ZW: Long non-coding RNA-LET is a positive prognostic factor and exhibits tumor-suppressive activity in gallbladder cancer. Mol Carcinog 54: 1397-1406, 2015.

18. World Health Organization: Obesity: Preventing and managing the global epidemic. Report of a WHO consultation. World Health Organ Tech Rep Ser 894: i-xii, 1-253, 2000.

19. Takeno S, Noguchi T, Takahashi Y, Fumoto S, Shibata T and Kawahara K: Assessment of clinical outcome in patients with esophageal squamous cell carcinoma using TNM classification score and molecular biological classification. Ann Surg Oncol 14: 1431-1438, 2007.

20. Livak KJ and Schmittgen TD: Analysis of relative gene expression data using real-time quantitative PCR and the $2^{-\Delta \Delta \mathrm{Ct}}$ method. Methods 25: 402-408, 2001.

21. Huarte M, Guttman M, Feldser D, Garber M, Koziol MJ, Kenzelmann-Broz D, Khalil AM, Zuk O, Amit I, Rabani M, et al: A large intergenic noncoding RNA induced by p53 mediates global gene repression in the p53 response. Cell 142: 409-419, 2010

22. Zhang A, Xu M and Mo YY: Role of the IncRNA-p53 regulatory network in cancer. J Mol Cell Biol 6: 181-191, 2014.

23. Liu Q, Huang JG, Zhou N, Zhang Z, Zhang A, Lu Z, Wu F and Mo YY: LncRNA loc285194 is a p53-regulated tumor suppressor. Nucleic Acids Res 41: 4976-4987, 2013.
24. Ma XY, Wang JH, Wang JL, Ma CX, Wang XC and Liu FS: Malat1 as an evolutionarily conserved IncRNA, plays a positive role in regulating proliferation and maintaining undifferentiated status of early-stage hematopoietic cells. BMC Genomics 16: 676, 2015.

25. Kung JT, Colognori D and Lee JT: Long noncoding RNAs: Past, present and future. Genetics 193: 651-669, 2013.

26. Cheetham SW, Gruhl F, Mattick JS and Dinger ME: Long noncoding RNAs and the genetics of cancer. Br J Cancer 108: 2419-2425, 2013.

27. Kotake Y, Nakagawa T, Kitagawa K, Suzuki S, Liu N, Kitagawa M and Xiong Y: Long non-coding RNA ANRIL is required for the PRC2 recruitment to and silencing of p15 (INK4B) tumor suppressor gene. Oncogene 30: 1956-1962, 2011

28. Geng YJ, Xie SL, Li Q, Ma J and Wang GY: Large intervening non-coding RNA HOTAIR is associated with hepatocellular carcinoma progression. J Int Med Res 39: 2119-2128, 2011.

29. Gupta RA, Shah N, Wang KC, Kim J, Horlings HM, Wong DJ, Tsai MC, Hung T, Argani P, Rinn JL, et al: Long non-coding RNA HOTAIR reprograms chromatin state to promote cancer metastasis. Nature 464: 1071-1076, 2010.

30. Niinuma T, Suzuki H, Nojima M, Nosho K, Yamamoto $H$, Takamaru H, Yamamoto E, Maruyama R, Nobuoka T, Miyazaki Y, et al: Upregulation of miR-196a and HOTAIR drive malignant character in gastrointestinal stromal tumors. Cancer Res 72: 1126-1136, 2012

31. Matouk IJ, DeGroot N, Mezan S, Ayesh S, Abu-lail R, Hochberg A and Galun E: The H19 non-coding RNA is essential for human tumor growth. PLoS One 2: e845, 2007.

32. Berteaux N, Lottin S, Monté D, Pinte S, Quatannens B, Coll J, Hondermarck H, Curgy JJ, Dugimont T and Adriaenssens E: H19 mRNA-like noncoding RNA promotes breast cancer cell proliferation through positive control by E2F1. J Biol Chem 280: 29625-29636, 2005.

33. Barsyte-Lovejoy D, Lau SK, Boutros PC, Khosravi F, Jurisica I, Andrulis IL, Tsao MS and Penn LZ: The c-Myc oncogene directly induces the H19 noncoding RNA by allele-specific binding to potentiate tumorigenesis. Cancer Res 66: 5330-5337, 2006.

34. Wang P, Ren Z and Sun P: Overexpression of the long non-coding RNA MEG3 impairs in vitro glioma cell proliferation. J Cell Biochem 113: 1868-1874, 2012.

35. Anwar SL, Krech T, Hasemeier B, Schipper E, Schweitzer N, Vogel A, Kreipe H and Lehmann U: Loss of imprinting and allelic switching at the DLK1-MEG3 locus in human hepatocellular carcinoma. PLoS One 7: e49462, 2012.

36. Lu KH, Li W, Liu XH, Sun M, Zhang ML, Wu WQ, Xie WP and Hou YY: Long non-coding RNA MEG3 inhibits NSCLC cells proliferation and induces apoptosis by affecting p53 expression. BMC Cancer 13: 461, 2013.

37. Sun M, Xia R, Jin F, Xu T, Liu Z, De W and Liu X: Downregulated long noncoding RNA MEG3 is associated with poor prognosis and promotes cell proliferation in gastric cancer. Tumour Biol 35: 1065-1073, 2014.

38. Vousden KH and Prives C: Blinded by the Light: The growing complexity of p53. Cell 137: 413-431, 2009. 